\title{
Epidemiological Studies of Diabetes Mellitus in Denmark
}

\section{A Case Finding Method Based on the National Service Conscript Registry}

\author{
A. Green, M. Hauge, N. V. Holm, and L. L. Rasch \\ University Institute of Clinical Genetics, Odense, Denmark
}

Summary. To provide unbiased material for epidemiological studies of diabetes mellitus a case finding method based on the Danish National Service Conscript Registry and death certificates is presented and discussed. Eight Danish total male birth cohorts, totalling 320162 persons, have been observed as to the occurrence of diabetes mellitus during the first twenty years of life, and it is concluded that the conscript registry represents an ideal basis for case identification, if the individual cases are further elucidated. The material is estimated to be about $95 \%$ complete. The main source of error originates from omissions when the registries are scrutinized. The cumulative incidence rates for the birth cohorts range from 1.3 to 3.2 per thousand; in the total material 2.4 per thousand.

Key words: Epidemiology, early onset diabetes mellitus, conscript registries, death certificates, incidence.

Epidemiological studies of diabetes mellitus (DM) are necessary to provide a basis for studies of the aetiology of the disease, to provide population data for genetic counselling and to aid planning of the health care system with particular respect to DM.

Apart from screening exercises for DM, which involve a cross-sectional sample of the population, epidemiological studies are traditionally based on hospital records with additional data from general practitioners [1, 2, 4], or death certificates [5]. The validity of such material depends on a series of assumptions, not all of which are necessarily valid, but no studies have so far analyzed the completeness and selection bias in a hospital or death certificate material.
The purpose of the present study was to establish and validate a new case finding method for DM: a registration of all cases of $\mathrm{DM}$ during the first 20 years of life in a series of Danish male birth cohorts, based on the Danish National Service Conscript Registry and supplemented by death certificates. Detailed epidemiological analyses will be presented subsequently.

\section{Materials and Methods}

Every Danish male citizen who has reached the age of 18 years is legally obliged to appear before a conscript registry board. A person with DM will be rejected unconditionally, if the disease is certified by a doctor. If a person, healthy at the examination, develops DM before his military duty is initiated, he will be reexamined and rejected by the board at the latest when he appears at the place of the military duty. The minimum age at the time of examination is 17 years, but in general is $18-19$ years; however occasionally the examination may be postponed until the age of 26 years.

Denmark is administratively divided into 7 conscript board districts, and people liable for military duty are allocated to districts according to their address at the time of examination. Over several decades the examination, and administration of the registries, have followed the same guidelines all over the country. In addition to personal data for each person, a medical record is established, including medical certificates for those rejected.

The present study is based on an investigation of all medical records for persons, from the Danish male birth cohorts of 1949-1956 inclusive, who were rejected by the conscript boards. The study was closed in July 1977 at which time the youngest person in the cohorts had reached the age of $20^{1 / 2}$ years. In every case when DM or suspected DM (glycosuria, renal glycosuria, transitory glycosuria, "renal diabetes", "latent diabetes", and unspecified carbohydrate intolerance) was given as the cause of rejection, date and place of birth, present address and time and place of the conscript board examination were recorded. Additionally, all available medical data were recorded (disease duration, kind of treatment, admissions to hospital, name and address of certifying doctor).

In order to include diabetics from the cohorts under study who died prior to the conscript board examination all death certificates 
Table 1. Cases of diabetes mellitus diagnosed before the age of 20 years obtained from conscript registries and death certificates, in the Danish male birth cohorts 1949-1956, inclusive

\begin{tabular}{lllc}
\hline & $\begin{array}{l}\text { Files of the } \\
\text { conscript } \\
\text { registries }\end{array}$ & $\begin{array}{l}\text { Register } \\
\text { of death } \\
\text { certificates }\end{array}$ & Total \\
\hline Primary number of cases & 856 & 37 & 893 \\
Excluded: & 10 & 0 & 10 \\
$\quad$ Born outside Denmark & 0 & 9 & 9 \\
Known previously & 25 & 3 & 28 \\
$\quad$ Not DM & 73 & 4 & 77 \\
$\quad$ Diagnosis after 20th birthday & 748 & 21 & 769 \\
Final number & & & \\
\hline
\end{tabular}

Table 2. The final material distributed on cohorts and age at the conscript board examination

\begin{tabular}{|c|c|c|c|c|c|c|c|c|c|}
\hline \multirow[b]{2}{*}{$\begin{array}{l}\text { Age at the conscript } \\
\text { board examination } \\
\text { (years) }\end{array}$} & \multicolumn{9}{|c|}{ Birth cohort } \\
\hline & 1949 & 1950 & 1951 & 1952 & 1953 & 1954 & 1955 & 1956 & Total \\
\hline$<20$ & 41 & 93 & 87 & 79 & 89 & 102 & 91 & 125 & 707 \\
\hline 20 & 5 & 4 & 3 & 6 & 6 & 3 & 5 & 0 & 32 \\
\hline 21 & 2 & 2 & 0 & 0 & 2 & 0 & 2 & 0 & 8 \\
\hline 22 & 0 & 0 & 0 & 0 & 0 & 0 & 0 & a & 0 \\
\hline 23 & 0 & 1 & 0 & 0 & 0 & 0 & $\mathrm{a}$ & a & 1 \\
\hline$>23$ & 0 & 0 & 0 & 0 & 0 & $\mathrm{a}$ & a & a & 0 \\
\hline Cases from death certificates & 4 & 3 & 2 & 2 & 3 & 4 & 0 & 3 & 21 \\
\hline Total & 52 & 103 & 92 & 87 & 100 & 109 & 98 & 128 & 769 \\
\hline Number in birth cohort ${ }^{b}$ & 41117 & 40734 & 39608 & 39632 & 40499 & 39309 & 39725 & 39538 & 320162 \\
\hline $\begin{array}{l}\text { Cumulative incidence rate } \\
\text { (per 1000) } 0-19 \text { years, inclusive }\end{array}$ & 1.3 & 2.5 & 2.3 & 2.2 & 2.5 & 2.8 & 2.5 & 3.2 & 2.4 \\
\hline $1 \mathrm{SEM}$ & 0.2 & 0.3 & 0.2 & 0.2 & 0.3 & 0.3 & 0.3 & 0.3 & 0.1 \\
\hline
\end{tabular}

${ }^{a}$ Not investigated

b Source: Statistisk Tabelværk 1962: I, and Statistisk Tabelværk 1973: XI, Danmarks Statistik, Copenhagen

with DM or complications of DM given as the primary or contributory cause of death from the cohorts were obtained from the Danish Institute of Clinical Epidemiology in Copenhagen. At this institute a registry based on the death certificates in the National Health Service of Denmark, and comprising the coded material of all deaths in Denmark since 1943, is established.

For each of the cases identified by these methods hospital records were traced and scrutinized in order to verify and establish the time of diagnosis of DM. If admission data were not available in the conscript board registries or from the death certificates, the files of the two main Danish diabetes hospitals (Steno Memorial Hospital and Hvidøre Hospital) were examined and, if the persons were not found there, we contacted the regional hospitals according to the address of the persons in question. Hospital records were systematically examined for the first admission with DM, irrespective of hospital.

The only criterion used to verify DM was that DM should be diagnosed by a doctor. The time of diagnosis, and correspondingly the age at diagnosis, referred to the time when the diagnosis was established in this way. Additionally, data on address at the time of diagnosis and duration of symptoms were obtained.
Relevant information was obtained in this way for all cases, except for 3 in which the data required was obtained from general practitioners. Only cases diagnosed before the age of 20 years were included, because the conscript registries will only include all cases of DM diagnosed during the first twenty years of life.

\section{Results}

In the conscript registries were found 856 persons with DM or suspected DM. Ten were excluded, because they were born outside Denmark, and an additional 25 were excluded because it was certified that they did not suffer from DM. Finally, 73 were excluded because the diagnosis was established after the day on which the subject achieved the age of 20 years. 
Thirty-seven death certificates with DM or complications of DM given as the primary or contributory cause of death were found. However, 9 persons were known previously from the conscript registries, 2 were excluded, because it was certified that they did not suffer from DM, and one was a female. Finally, 4 persons were excluded because of too high an age at diagnosis. Thus, the final material comprised 748 persons from the conscript registries and 21 persons from the death certificates (Table 1).

Table 2 shows the distribution of the cases in the individual birth cohorts, as well as the distribution at time of examination for cases from the conscript registries and the cumulative incidence rates. It can be seen by a comparison of the $95 \%$ confidence intervals (the cumulative incidence rate \pm 2 SEM) that the 1949 cohort has a significantly lower rate compared with the other cohorts.

Finally, it should be mentioned that the geographical distribution of the cases corresponded very well to the distribution of the total birth cohorts. This applies to the time of birth as well as the time of the conscript board examination.

\section{Discussion}

The conscript board registries represent a previously unused, but valuable source for epidemiological studies of diseases occurring during the first twenty years of life. In Denmark, the registries cover all young males, irrespective of their health status or their eventual later exemption from military service. It is an additional advantage that all conscript board files in Denmark have been handled according to the same rules for several decades. Finally, Denmark represents an ideal basis for epidemiological studies because of [1] the homogeneous and stable population, [2] the uniform health care system and [3] access to detailed vital statistics and public registries. In spite of these favourable conditions, a series of possible errors associated with this case finding method exists.

Persons who have emigrated before the age of the conscript board examination will not be included; a total of 23178 males from the birth cohorts under study emigrated prior to the age of 20 years, and as the annual incidence of DM among males aged 0-20 years in Denmark is 12 per $100000[1,2]$ it can be estimated that these emigrants should include 56 diabetics. However, as several may have been diagnosed after emigration, the error introduced must be small and will not be considered further.

Some fatal cases may have been missed due to the lack of recording of DM on the death certificates or to misclassification. These errors are probably small: first, the number of deceased persons is small compared to those surviving the first 20 years of life, and second, it seems reasonable to assume that deaths among young persons will be particularly carefully evaluated.

Persons suffering from DM together with mental disorders or together with other diseases belonging to the same category of rejection as DM (chronic polyarthritis, pernicious anaemia, leukaemia, haemophilia, thyrotoxicosis and other endocrine diseases) may be rejected with one of these diseases, but not $\mathrm{DM}$, given in the medical record. However, the number of such cases in the age group concerned must be extremely small, and correspondingly, the error negligible. For instance, based on data from the Danish Social Service it can be estimated that the cohorts under study will include only 7 diabetics who are under the care of the service.

Some diabetics from the youngest cohorts may have postponed the conscript board examination until after the closing of our study. But our data indicate that diabetics in general will be examined and rejected by the earliest possible date, as only 9 persons $(1.2 \%)$ had an age of 21 years or more at the time of examination (Table 2).

The most important source of error is supposed to be omissions when perusing the files in the conscript board districts. In order to elucidate this error we have compared parts of the present material with two other studies, conducted independently. From the prevalence population of all insulin treated diabetics in a $10 \%$ sample of the Danish population as on July 1, 1973 (Green et al., unpublished observations), we have drawn all males who fulfilled the criteria for inclusion in the present study, totalling 74 persons. In the present material, 70 persons fulfilled the criteria for inclusion in the prevalence population mentioned. The combined group comprised 75 persons, as one was included in the present, but not in the prevalence material, and 5 were included in the latter, but not in the present material. Of these 5 cases, 3 represented omissions, and 2 represented other kinds of error discussed earlier.

From Christau et al.'s study $[1,2]$ of insulindependent DM diagnosed during 1970-1977 in different parts of Denmark were drawn all cases which should also be included in the present study, totalling 66 persons. On the other hand, 72 cases from our study fulfilled the criteria for inclusion in Christau et al.'s study, and the combined group comprised 75 persons, as 9 were included in the present, but not in the other study, and 3 were included in their, but not in our study. These 3 cases represented kinds of error discussed earlier, but not omissions. 
Combining all sources of error the deficit in the present material can be estimated to be about $5 \%$, the most important error being omissions when perusing the files. Therefore, it is concluded that the conscript board registries represent an ideal basis for epidemiological studies of DM. It is, however, necessary to obtain clinical data for all cases involved in order to verify and establish the time of diagnosis.

Our study shows that the cumulative incidence rate of DM in males during the first 20 years of life is 2.4 per thousand. This is in accordance with estimates based on data from Christy et al. [3]. We have no obvious explanation as to the small rate (1.3 per thousand) in the oldest (1949) cohort.

The DM cases were distributed throughout the different parts of Denmark according to the distribution of the total birth cohorts. However, this does not exclude the possibility of variation in incidence between, for instance, rural and urbanized regions or between areas with different socio-economic structures, as suggested by Christau et al. [1]. This will be the subject for a subsequent report together with a discussion of the clinical and detailed epidemiological findings.

Acknowledgements. The authors want to thank Dr. G. Funding who suggested the use of the Danish Nationai Conscript Registry and the Danish Ministry of the Interior for giving access to the registries and for practical support from the staffs of the registries. Access to hospital records was given by the heads of all medical and paediatric departments in Denmark. We want especially to thank the Chief Physicians of the Steno Memorial Hospital and Hvidøre Hospital and Dr. B. Christau for kind cooperation.
Secretarial assistance was given by Mrs. Anette Rasmussen.

The study was financially supported by grants from the Danish Diabetic Association (Landsforeningen for Sukkersyge) and Dr. med. Erik Garde og Elisabeth Gardes Legat. During the initial part of the study A.G. received a fellowship from the Danish Medical Research Council (grant no. 512-7419).

\section{References}

1. Christau B, Kromann H, Andersen OO, Christy M, Buschard K, Arnung K, Kristensen IH, Peitersen B, Steinrud J, Nerup J (1977) Incidence, seasonal and geographical patterns of juvenile-onset insulin-dependent diabetes mellitus in Denmark. Diabetologia 13: 281-284

2. Christau B, Kromann $H$, Christy M, Ortved Andersen O, Nerup J (1979) Incidence of insulin-dependent diabetes mellitus (0-29 years at onset) in Denmark. Acta Med Scand [Suppl] 624: 54-60

3. Christy M, Green A, Christau B, Kromann H, Nerup J (1979) Epidemiologic studies of insulin-dependent diabetes mellitus. Diabetes Care 2: 127-130

4. Falconer DS, Duncan LJP, Smith C (1971) A statistical and genetical study of diabetes. I. Prevalence and morbidity. Ann Hum Genet 34: 347-369

5. Grönberg A, Larsson T, Jung J (1967) Diabetes in Sweden. A clinico-statistical epidemiological and genetic study of hospital patients and death certificates. Esselte AB, Stockholm

Received: January 17, 1980,

and in revised form: June 11, 1980

Dr. Anders Green

University Institute of Clinical Genetics

J. B. Winsløwsvej 17

DK-5000 Odense C

Denmark 